\title{
Effects of subcutaneous melatonin implants on reproductive seasonality of farmed fallow deer (Dama dama)
}

\author{
G. W. Asher, G. K. Barrell*, J. L. Adam and L. D. Staples $\dagger$ \\ Ruakura Agricultural Centre, Ministry of Agriculture and Fisheries, Private Bag, Hamilton, New \\ Zealand; *Animal and Veterinary Sciences Group, Lincoln College, Canterbury, New Zealand; and \\ $\uparrow$ Department of Agriculture \& Rural Affairs, Animal Research Institute, Werribee, Victoria 3030 , \\ Australia
}

\begin{abstract}
Summary. A total of 18 fallow does, including pubertal, non-pregnant and pregnant adult does (6 per class), each received a single subcutaneous implant containing $18 \mathrm{mg}$ melatonin on 4 occasions at 29-30-day intervals from 10 November 1986 ( 120-day treatment period). A further 18 contemporary does served as herd-mate controls. Two adult fallow bucks were treated the same and were run with the does until $16 \mathrm{March}$. Thereafter, 1 of 4 control bucks was run with the does until 1 June. Of the 6 pregnant does receiving implants within the last 40 days of their gestation, 4 failed to lactate after parturition in December 1986. The remaining 2 does successfully reared their fawns, as did the 6 contemporary controls. Mean ( \pm s.e.m.) dates of first oestrus in 1987 were 27.6 February ( \pm 3.0 days) and 22.9 April ( \pm 0.8 days) for all treated and all control does respectively $(P<0.001)$. Pubertal does were generally later to exhibit first oestrus than were older does within their respective treatment groups. Return oestrus occurred only in 2 pubertal does ( 1 treated and 1 control) with remaining does conceiving to their first oestrus, as verified by plasma progesterone profiles. However, $5(28 \%)$ of the treated does and $3(17 \%)$ of the control does failed to maintain pregnancy and fawn in 1987. The mean ( \pm s.e.m.) 1987 fawning date of the remaining does was 22.4 October ( \pm 2.7 days) for the treated group $(N=13)$ and 13.1 December $( \pm 0.8$ days $)$ for the control group $(\mathrm{N}=15 ; P<0.001)$. Mean $( \pm$ s.e.m.) gestation length of treated does $(238.9 \pm 0.6$ days $)$ was significantly longer than that of control does $(234.5 \pm 0.4$ days; $P<0.001)$. Of 13 fawns born to treated does, $4(31 \%)$ died within $24 \mathrm{~h}$ of birth (mainly due to hypothermia) whereas all 15 fawns born to control does survived to weaning.

Melatonin-treated bucks exhibited a marked advancement of neck muscle hypertrophy during the treatment period and displayed normal rutting activity (e.g. vocalization) in response to early oestrus in the treated does.
\end{abstract}

Keywords: fallow deer; Dama dama; reproduction; melatonin; oestrus; progesterone

\section{Introduction}

Fallow deer are highly seasonal breeders, with the onset of rutting activity of bucks and the occurrence of first oestrus in does coinciding during autumn (Chapman \& Chapman, 1975; Asher, 1985). After a 234-day gestation period, fawns are born during the summer months (Asher \& Adam, 1985; Asher, 1987). In New Zealand, the fawning season and subsequent lactation occur at a time of deteriorating pasture quality. Advancing the fawning season by up to 2 months would align peak pasture production of spring with the high energy demands of lactation.

The breeding season of fallow deer and other temperate-zone cervids is under photoperiodic control (Marshall, 1937). This control is mediated by circadian variations in the secretion of the 
pineal hormone, melatonin (Bittman et al., 1983). Daily melatonin administration during long photoperiods induces early reproductive function in anoestrous ewes when given orally (Kennaway et al., 1982; Arendt et al., 1983) or intramuscularly (Nett \& Niswender, 1982). Administration of continuous doses of melatonin to ewes via soluble glass intraruminal boluses (Poulton et al., 1987) or subcutaneous implants (English et al., 1986) has also been effective in advancing the onset of oestrus. Various means of melatonin administration to white-tailed deer (Odocoileus virginianus) bucks (Bubenik, 1983) and red deer (Cervus elaphus) hinds (Adam \& Atkinson, 1984; Nowak et al., 1985; Webster \& Barrell, 1985) and stags (Adam \& Atkinson, 1984; Lincoln et al., 1984) advance the onset of the breeding season and shift seasonal moult cycles. Daily oral administration of melatonin for a 45-day period in summer to male fallow deer also advances the seasonal attainment of fertility (Asher et al., 1987).

The present study was conducted to determine the efficacy of subcutaneous melatonin implants in advancing the fawning season of farmed fallow deer in southern temperate regions (i.e. Ruakura Agricultural Centre; $37^{\circ} 46^{\prime} \mathrm{S}, 175^{\circ} 20^{\prime} \mathrm{E}$ ).

\section{Materials and Methods}

\section{Experiment 1: evaluation of the efficacy of melatonin implants to elevate plasma melatonin concentrations}

Implants, each containing $18 \mathrm{mg}$ melatonin (Regulin Batch 1000695-1; Regulin Ltd, Melbourne, Australia), were inserted s.c. at the base of the ear using an 8-gauge stainless-steel trocar. Four fallow does (18 months old; $36.0 \pm 0.8 \mathrm{~kg}$ ) each received a single melatonin implant on $24 \mathrm{June}$ 1987. A further 4 does of the same age and similar liveweight $(35.7 \pm 1.0 \mathrm{~kg}$ ) served as controls. All 8 does were blood sampled $(5 \mathrm{ml}$ heparinized Vacutainers), contralateral to the implantation site, at 2-h intervals for $24 \mathrm{~h}$, starting at $08: 00 \mathrm{~h} 25$ June (24-48 h from implantation) and 08:00 h 15 July (21-22 days from implantation). Additional blood samples were collected at dusk $(\sim 17: 00 \mathrm{~h})$ and dawn $(\sim 07: 00 \mathrm{~h})$ on both days. During the two blood-sampling sessions, the does were kept indoors but under natural lighting regimens. Night-time samples were collected under subdued red light. All samples were centrifuged immediately after collection and plasma was stored at $-10^{\circ} \mathrm{C}$ until assayed for melatonin.

\section{Experiment 2: effect of melatonin implants on the breeding season}

Animals and management. A total of 36 fallow does, comprising 12 pubertal does (11 months old), 12 nonpregnant adult does ( $>5$ years old) and 12 pregnant does ( $>5$ years old), were allocated to Exp. 2 in early November 1986. The pubertal does and non-pregnant adult does were run together throughout the period from 10 November 1986 to 23 September 1987 . The pregnant does were run separately from the other does until their December 1986-born fawns were weaned on 16 March 1987; thereafter they were run with the other 24 does.

The non-pregnant adult does had been run with a vasectomized buck during the 1986 breeding season (AprilSeptember) for use in unrelated studies but all had histories of normal pregnancies. The pregnant does had previously had their first oestrus of the 1986 breeding season synchronized in early May by use of $12 \%$ progesterone CIDRs (CIDR-type S; N.Z. Dairy Board, Hamilton, N.Z.) as described by Asher et al. (1986). All 12 does conceived to the synchronized oestrus and were expected to fawn around 25 December 1986.

Six mature, polled bucks ( 5 years old) were selected for the trial ( 2 treated and 4 controls). Single, melatonintreated bucks were run with each of the 2 groups of does (i.e. pubertal/non-pregnant and pregnant) throughout the period from 10 November 1986 to 16 March 1987. Thereafter, a single non-treated buck was run with the combined group of does until 1 June 1987. The remaining 3 control bucks were not used as sires.

The does were allocated to one of 2 fawning groups, depending on their expected 1987 fawning dates, on 23 September 1987. Throughout the entire trial period, the deer were grazed on ryegrass-white clover pastures. Meadow hay was provided ad libitum in racks throughout winter (June-August 1987).

Melatonin treatment. Six does within each age and pregnancy class $(\mathrm{N}=18$ total) each received a single implant on 10 November, 10 December, 8 January and 9 February (i.e. 29-30-day intervals). Treated and untreated classes were balanced for liveweight on 10 November 1986. Two bucks each received a single implant on the same dates. A further 4 bucks of the same age received no implants and served as controls.

Blood sampling of does. Pubertal and non-pregnant adult does were blood-sampled twice weekly (Monday/ Thursday) from 10 November 1986 to 1 June 1987. The pregnant does were sampled at the same times except for the period between 12 January and 16 February 1987 (early lactation) when they were sampled weekly (Monday). Additional samples were collected from the melatonin-treated does on the day following each implantation. 
Blood was collected into heparinized Vacutainers by jugular venepuncture, either ipsilateral ( 10 November 1986 to 5 January 1987) or contralateral (8 January to 1 June 1987) to the implantation site, while the deer were restrained in a cradle device. Samples were centrifuged $(2000 \mathrm{~g}$ for $25 \mathrm{~min}$ ) within $30 \mathrm{~min}$ of collection, the plasma transferred to plastic vials and stored at $-10^{\circ} \mathrm{C}$ until assayed.

Liveweight and neck girth recording. All does were weighed weekly (Monday) from 10 November 1986 to 1 June 1987, then fortnightly until about 1 week before the expected onset of fawning of treated (i.e. early October) or untreated (i.e. early December) does in 1987 . Thereafter, they were weighed monthly during lactation. The bucks were weighed and their neck girths measured (after Asher et al., 1987) at 2-week or monthly intervals from November 1986 to November 1987.

Detection of oestrus. All bucks running with does were fitted with ram mating harnesses (Asher, 1985) between 1 February and 1 June 1987. Crayons were replaced every 3 or 4 days and daily observations were conducted from an enclosed observation tower to record crayon mating marks. Crayon colours were changed at 21-day intervals.

Fawning data. All fawns born in December 1986 and between October and December 1987 were tagged and weighed within $12 \mathrm{~h}$ of birth. They were identified to their dam either by direct observation of parturition or multiple observations of sucking activity (Asher \& Adam, 1985).

\section{Hormone radioimmunoassays}

Plasma progesterone concentrations were measured by a procedure similar to that described by Fairclough $e$ t al. (1975) and that has been validated previously for fallow deer serum (Asher, 1985). The antiserum was raised in a rabbit against progesterone-11-BSA conjugate and used at a final dilution of 1:3000. The only significant crossreaction of a wide range of steroids tested in the assay was cholesterol $(1.5 \%)$. Sensitivity of the standard curve was $0.03 \mathrm{ng}$ per tube $(0.48 \mathrm{nmol} / 1$ plasma) and the intra- and inter-assay coefficients of variation were $9.2 \%$ and $11.0 \%$ respectively.

Plasma melatonin concentrations were measured in duplicate samples of plasma $(0.5 \mathrm{ml})$ by direct radioimmunoassay as described for human plasma by Fraser $e t$ al. (1983). The antiserum (704/8483 Guildhay Antisera, University of Surrey, Guildford, U.K.) was raised in a sheep against $\mathrm{N}$-acetyl-5-methoxytryptophan-bovine thyroglobulin and was used at a final dilution of 1:8000. Cross-reactivities at the $50 \%$ displacement level were as follows: $N$-acetyltryptamine $(0.97 \%)$, 6-hydroxymelatonin $(0.38 \%)$ and $N$-acetyltryptophan $(0.26 \%)$. Serial dilutions of pooled plasma samples from newly implanted does with high concentrations of immunoreactive melatonin gave inhibition curves parallel to those generated for melatonin in buffer. All samples from an individual were included within a single assay. Low, medium and high melatonin control samples were included at frequent intervals in each assay. The inter-assay coefficients of variation were $8.5 \%$ for the low control $(n=11$; mean $=0.19 \mathrm{nmol} / \mathrm{l}), 10.3 \%$ for the medium control $(n=1 \mathrm{I}$; mean $=0.27 \mathrm{nmol} / \mathrm{l})$ and $5.5 \%$ for the high control samples $(n=14$; mean $=0.72 \mathrm{nmol} / \mathrm{l})$. The intra-assay coefficients of variation were $8.8,7.6$ and $6.9 \%$ respectively for the 3 control samples. Sensitivity, defined as the first point on the standard curve that was significantly different from zero, was $0.03 \mathrm{nmol} / 1$.

\section{Statistical analysis}

Data are expressed as a mean \pm 1 s.e.m. Differences between means were analysed by Student's $t$ test and differences between proportions were examined by $\chi^{2}$ analysis.

\section{Results}

\section{Effects of implants on plasma melatonin concentrations}

The 24-h profiles of mean plasma melatonin concentrations of 4 contralateral implanted and 4 non-implanted does are presented in Fig. 1. Mean daytime melatonin concentrations $24 \mathrm{~h}$ after implantation ranged between 1.4 and $1.9 \mathrm{nmol} / 1$, whereas nocturnal concentrations were elevated to a maximum of $2.5 \mathrm{nmol} / 1$. By 21 days from implantation, mean daytime concentrations had declined to between 0.3 and $0.4 \mathrm{nmol} / 1$, with a peak nocturnal mean of $1.4 \mathrm{nmol} / 1$. By contrast, the non-implanted does had almost undetectable daytime plasma melatonin concentrations on both days. However, mean nocturnal concentrations were elevated in control does, with maximum values reaching $1.2 \mathrm{nmol} / \mathrm{l}$ (Day 1-2 samples) and 0.8 nmol/1 (Day 21-22 samples).

The profile of daytime melatonin concentrations in the plasma of 6 implanted non-pregnant does is shown in Fig. 2. The mean concentrations of samples collected ipsilateral to the implantation site attained peak values of $3.0 \mathrm{nmol} / \mathrm{l}$ and $5.0 \mathrm{nmol} / \mathrm{l}$ at 1 day after the administration of the 1 st and 2nd implant respectively. Similarly, mean values from contralateral plasma samples (3rd 


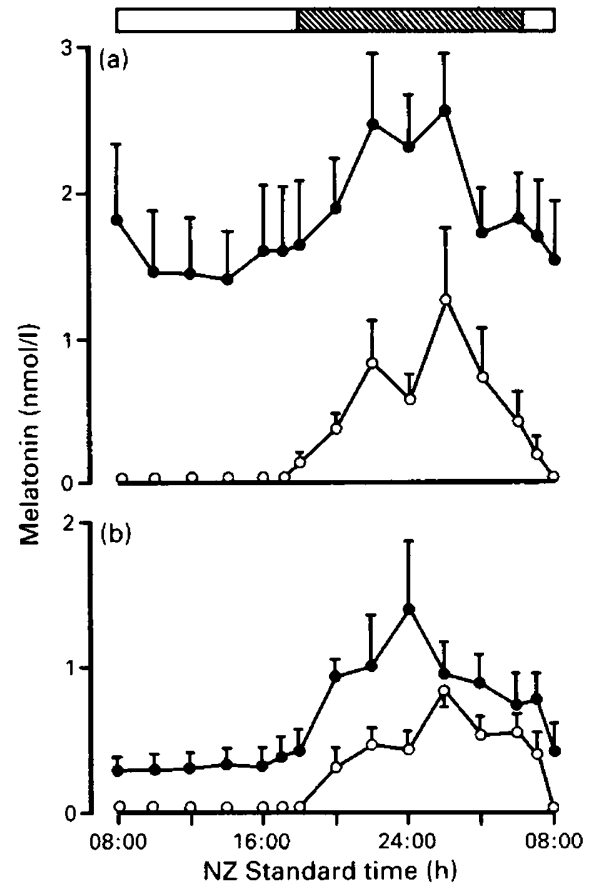

Fig. 1. The 24-h profiles of mean ( \pm s.e.m.) plasma melatonin concentrations of melatoninimplanted $(\mathrm{N}=4 ; \bigcirc)$ and control $(\mathrm{N}=4 ; \bigcirc)$ fallow does (a) 1-2 days after implantation and (b) 21-22 days after implantation. The shaded portion of the horizontal bar represents the duration of darkness. All samples were collected contralateral to the implantation site.

and 4th implants) were maximal 1 day after administration but were lower than for earlier ipsilateral samples ( 3.0 and $2.0 \mathrm{nmol} / \mathrm{l}$ respectively). In all cases, mean plasma melatonin concentrations declined erratically after peak values. However, reimplantation occurred before the complete exhaustion of previous implants and there appeared to be additive effects of old and new implants on mean plasma melatonin concentrations immediately after reimplantation. Declining mean plasma melatonin concentrations after the last implant were apparent for about 60 days, although mean contralateral values were $<0.3 \mathrm{nmol} / 1$ after 40 days.

\section{Effect of melatonin treatment during late pregnancy on fawn survival}

The mean fawning date of the 6 pregnant does receiving melatonin implants was 26.8 December ( $\pm 1 \cdot 1$ days) 1986. Four of the fawns died within 3 days of birth because their dams failed to lactate. The remaining 2 fawns were reared successfully. The mean fawning date of the 6 pregnant control does was 23.8 December ( \pm 0.8 days) 1986 and all 6 fawns were reared successfully.

\section{Oestrus and conception}

First oestrus of the 1987 breeding season was observed for 15 treated does $(83 \%)$ and 16 control does $(89 \%)$. For the remaining does the approximate date of 1 st oestrus was calculated from their plasma progesterone profiles based on twice-weekly samples. Return (2nd) oestrus was observed only for 2 pubertal does ( 1 treated and 1 control), and was confirmed from plasma progesterone profiles. There was no evidence of any other doe having exhibited oestrous cycles and individual plasma progesterone profiles indicate that conception occurred to 1 st $(94.4 \%)$ or 2 nd $(5.6 \%)$ oestrus, with no difference between treated and control does. 


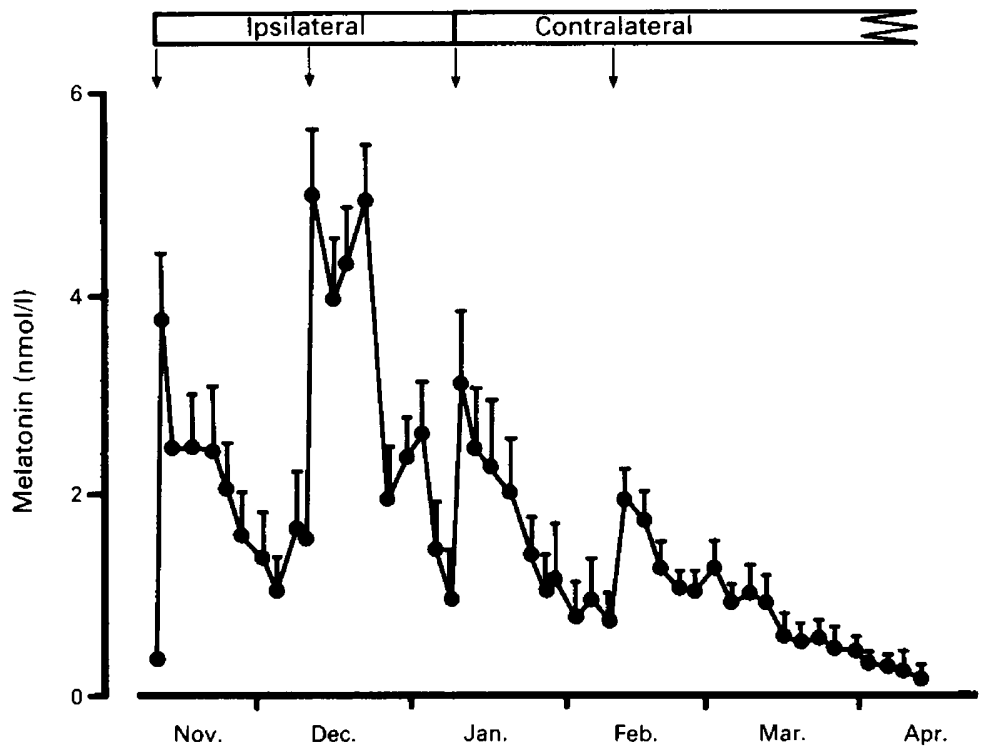

Fig. 2. Profile of mean ( \pm s.e.m.) daytime plasma melatonin concentrations of 6 non-pregnant adult fallow does each receiving melatonin implants on 4 occasions (indicated by arrows). The horizontal bar represents the period of implantation. Samples were obtained ipsilateral to the site of the 1st and 2 nd implants and contralateral to the site of the 3rd and 4th implants.

The mean date of first oestrus (Table 1$)$ was 27.6 February ( \pm 3.0 days) for treated does and 22.9 April ( \pm 0.8 days) for control does. There was no overlap between treated and control does in the incidence of 1st oestrus, although the spread of oestrus was wider for treated does (range: 17 February-6 April) than for control does (range: 18 April-28 April). Pubertal does generally exhibited their lst oestrus later than older does within their respective treatment groups although the difference in mean dates was significant $(P<0.05)$ only in the case of control does (Table 1$)$.

The 2 treated adult does that successfully reared their 1986-born fawns exhibited oestrus and conceived on 20 February and 4 March 1987 respectively, while they were still lactating.

Mean plasma progesterone profiles of the various age/reproductive classes of treated and control does are presented in Fig. 3. For the 12 adult does pregnant in 1986, plasma progesterone concentrations were elevated (15-20 nmol/1) during the later stages of pregnancy and declined rapidly after fawning in December 1986 (Figs 3a \& b). For all other groups of does, mean values were generally low $(<3 \mathrm{nmol} / \mathrm{l})$ during the same period, although erratic fluctuations $(0 \cdot 5-7 \mathrm{nmol} / \mathrm{l})$ were observed for the 2 pubertal groups (Figs $3 \mathrm{e} \& \mathrm{f}$ ). Mean plasma progesterone concentrations increased after oestrus in all groups of does, reaching values similar to those during late pregnancy (i.e. $15-20 \mathrm{nmol} / \mathrm{l}$ ). The rise in mean progesterone values occurred about 2 months earlier for treated than control groups.

\section{Fawning}

While plasma progesterone profiles clearly indicated that all 36 does in the trial conceived to either the 1 st or 2 nd oestrus, not all does maintained the pregnancy to term: $5(28 \%)$ of the melatonin-treated does and $3(17 \%)$ of the control does failed to fawn in $1987\left(P>0 \cdot 1 ; \chi^{2}\right.$ test). A return to oestrus was particularly prevalent for pubertal does $(42 \%)$, moderately so for the nonpregnant adult group (25\%) but not a feature of the does that had been pregnant in the previous season (Table 1). 


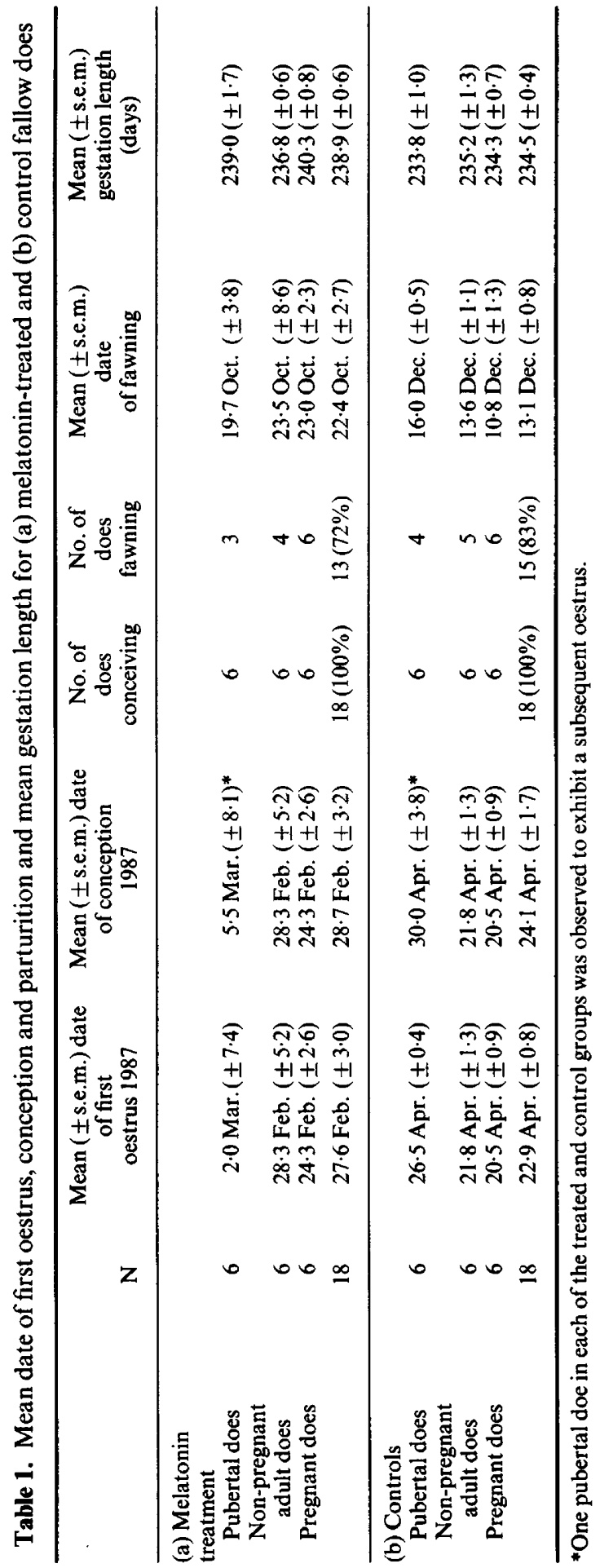



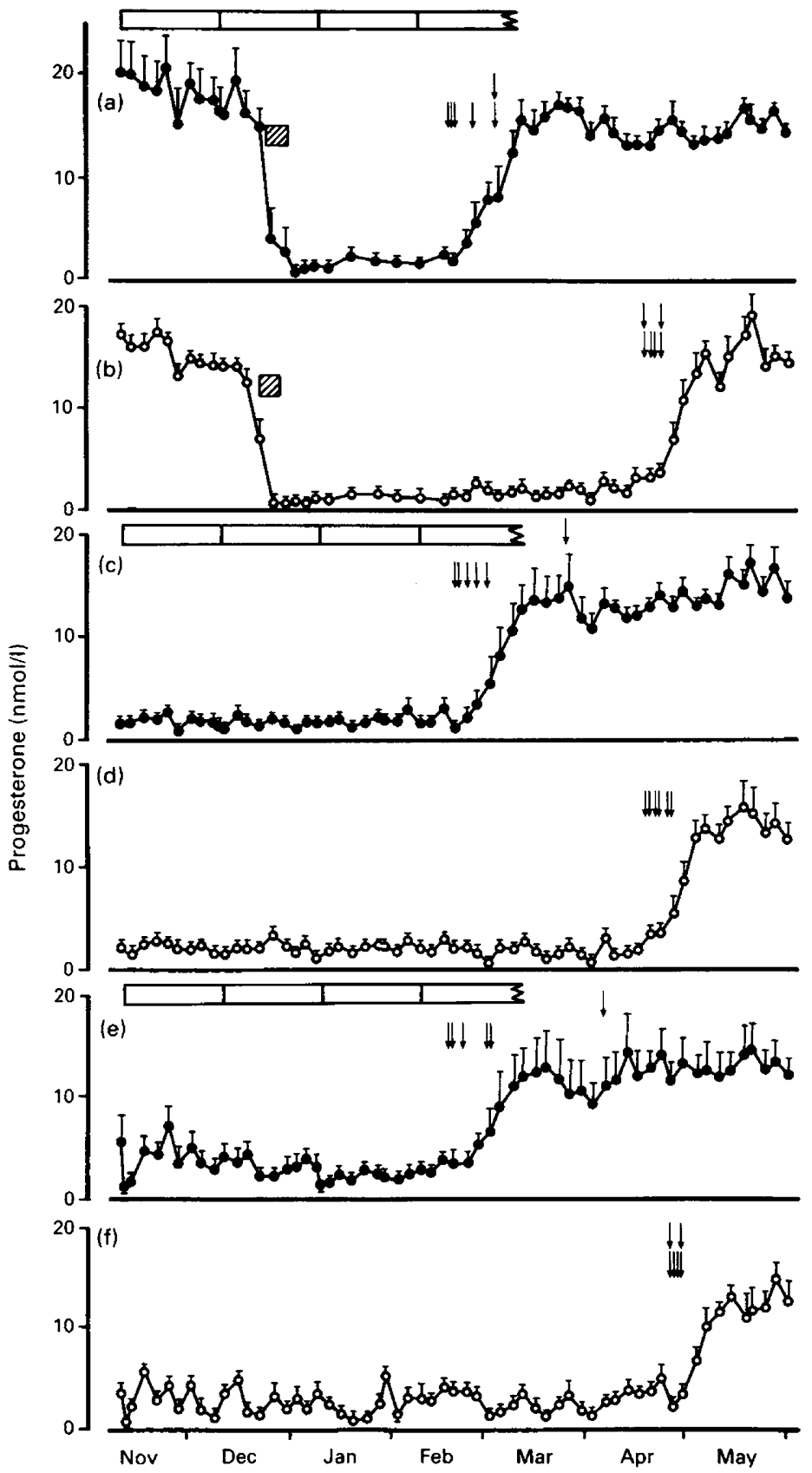

Fig. 3. Profiles of mean ( \pm s.e.m.) plasma progesterone concentrations of melatonin-implanted (O) and control $(O)$ pregnant does $(a, b)$, non-pregnant adult does $(c, d)$ and pubertal does (e, f) ( 6 does per group). Horizontal bars represent the period of implantation (i.e. a, $c$ and e), the shaded square represents the 1986 fawning period (i.e. $a$ and $b$ ) and arrows indicate the occurrence of first oestrus for each doe. 
The mean fawning date of the melatonin-treated does $(\mathrm{N}=13)$ was 22.4 October $( \pm 2.7$ days $)$ versus 13.1 December $( \pm 0 \cdot 8$ days) for the control does $(N=15)$. There was no overlap in fawning dates between the 2 groups, although the spread of births was greater for treated does (range: 13 October-18 November) than for control does (range: 7-18 December). These results represent only does that conceived to their 1st oestrus, as the 2 pubertal does that conceived to a return oestrus subsequently failed to fawn.

The mean gestation length of melatonin-treated does was significantly longer $(P<0.001)$ than that of control does, although only by $\sim 4$ days (Table 1 ).

Of the 13 fawns born early to melatonin-treated does, $4(31 \%)$ died within $24 \mathrm{~h}$ of birth. One was born non-viable $(2.7 \mathrm{~kg}$ birth weight) and 3 died from apparent hypothermia due to inclement weather. All 15 fawns born to the control does survived to weaning.

The mean birth weights of fawns born to melatonin-treated does (males $3.93 \pm 0.14 \mathrm{~kg}, \mathrm{~N}=8$; females $3.40 \pm 0.27 \mathrm{~kg}, \mathrm{~N}=5$ ) were not significantly different from those of fawns born to control does (males $4.08 \pm 0.20 \mathrm{~kg}, \mathrm{~N}=6$; females $3.43 \pm 0.14 \mathrm{~kg}, \mathrm{~N}=9$ ).

\section{Doe liveweight changes}

Profiles of mean liveweights of melatonin-treated and control does are presented in Fig. 4; the last portion (June-January) of the profiles representing only those does that fawned in 1987. During the period of melatonin treatment and up to the cessation of blood sampling (i.e. 10 November 1986-early June 1987), mean liveweights of melatonin-treated and control does within each of the age/reproductive status classes were not significantly different $(P>0 \cdot 1)$ although there was an apparent divergence in mean liveweights within the non-pregnant adult (Fig. $4 \mathrm{~b}$ ) and the pubertal (Fig. 4c) classes during the post-treatment period from early March to early June, with melatonin-treated does being lighter.

Melatonin-treated and control does that maintained pregnancy in $1987(\mathbf{N}=13$ and 15 , respectively) attained their peak 1987 liveweights immediately before fawning in October and December respectively. While the melatonin-treated does had lower mean pre-fawning liveweights than control does (i.e. $2 \cdot 0-3 \cdot 8 \mathrm{~kg}$ lighter) the differences were not significant for any class $(P>0 \cdot 1)$.

\section{, Effect of melatonin implants on reproductive seasonality of sire bucks}

Seasonal profiles of liveweights and neck girth changes of 2 melatonin-treated bucks, superimposed on the mean profiles for 4 control bucks of the same age, are presented in Fig. 5 . Both treated bucks gained weight ( $94-100 \mathrm{~g}$ /day) during most of the implantation period (10 November 1986-late January 1987) reaching 75 and $80 \mathrm{~kg}$ by the end of January. There was a rapid liveweight loss ( 433 to $467 \mathrm{~g} /$ day) over the 30 -day period from early February, the period corresponding to mating activity of the melatonin-treated deer. Liveweights fluctuated little over the subsequent 5-month period from early March to August.

The 4 control bucks had similar liveweight gains during the 1986/87 summer but continued gaining weight for a longer period to attain a peak mean liveweight of $86.6 \mathrm{~kg}$ about 1 month later than that of the melatonin-treated bucks. Furthermore, while rapid liveweight losses paralleled those of the treated bucks, they occurred about 2 months later, coincident with the natural rutting season in April. The magnitude of liveweight loss over the rutting periods was greater for the

Fig. 4. Profiles of mean ( \pm s.e.m.) liveweight of implanted $(\bullet)$ and control $(O)$ fallow does for a 14-month period from the start of melatonin treatment; (a) pregnant does; (b) non-pregnant adult does; (c) pubertal does ( 6 does per group for the period between November 1986 and June 1987; thereafter the profiles represent only those does that maintained pregnancy to term, as indicated on the graph). The fawning periods are represented by shaded (melatonin-treated groups) and stippled (control groups) bars. 

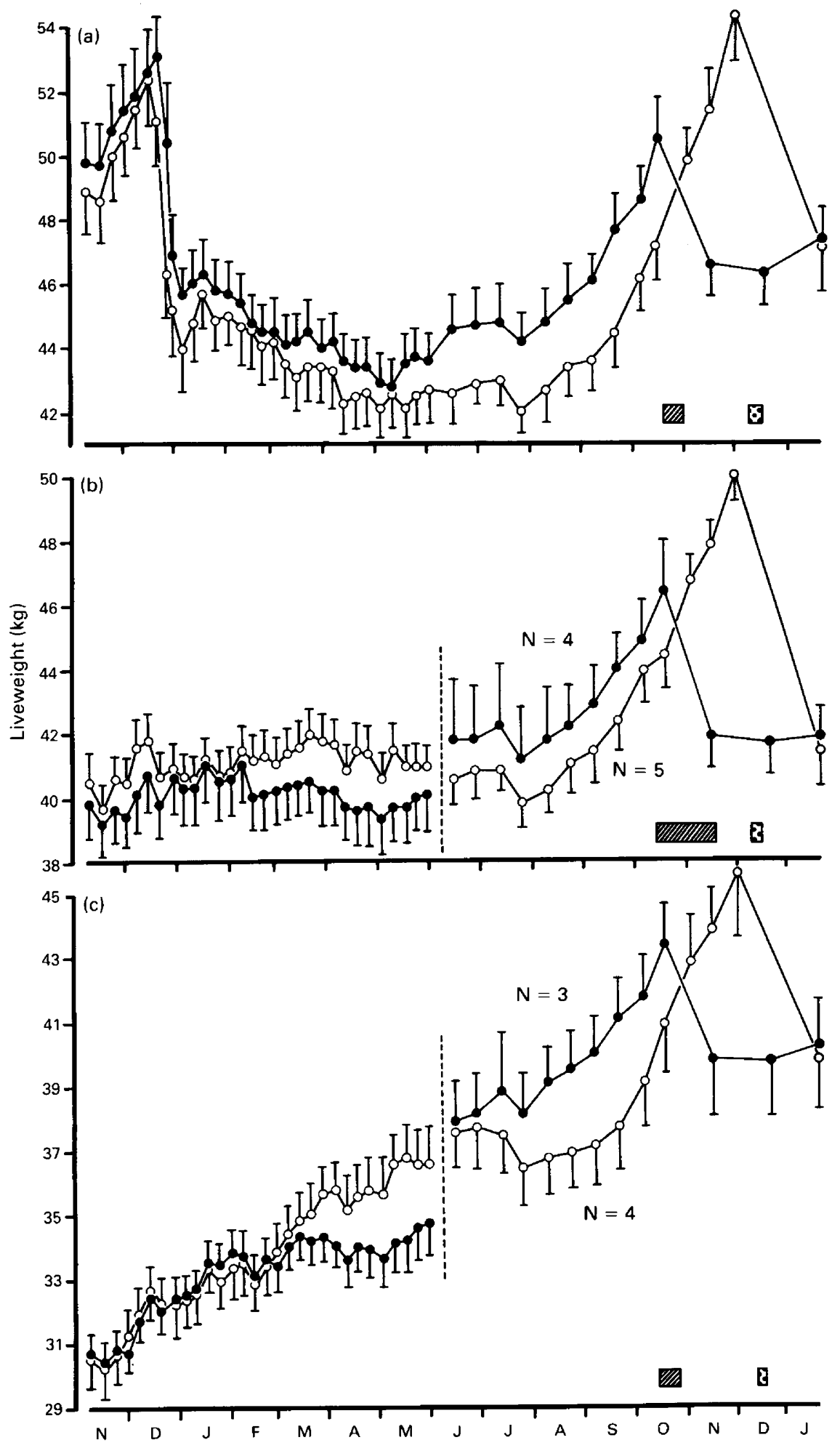


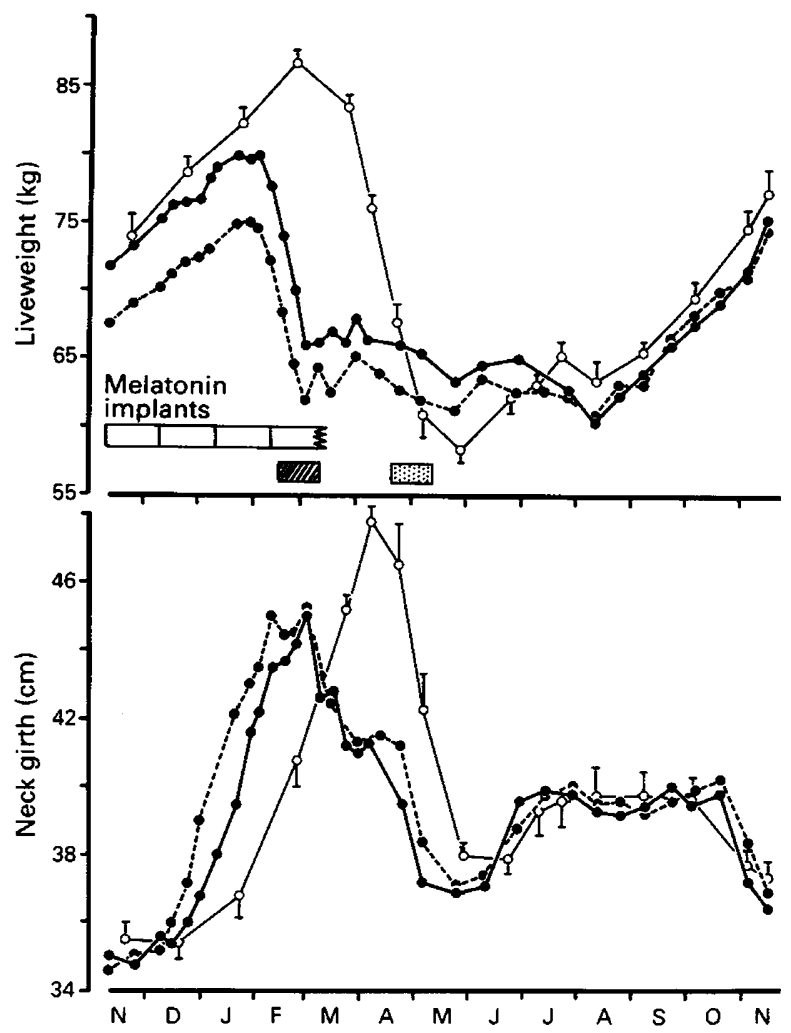

Fig. 5. Seasonal profiles of liveweight and neck girth changes of 2 fallow bucks with melatonin implants (O) superimposed on the mean ( \pm s.e.m.) profile for 4 control bucks $(O)$ of the same age. The period of melatonin treatment is represented as for Fig. 3 and the rutting periods of the treated and control bucks are indicated by the shaded and stippled bars respectively.

control bucks (mean: $28 \cdot 1 \mathrm{~kg} ; 32 \%$ ) than for the melatonin-treated bucks (13-14 kg; $17 \cdot 3-17 \cdot 5 \%$ ). Both groups of bucks re-established liveweight gains in August 1987.

The neck girth of the 2 melatonin-treated bucks rapidly increased during the treatment period, reaching maximum values in late February, about 2 months earlier than the control bucks (Fig. 5). Neck girths of treated and control bucks decreased over the respective rutting periods (February $v s$ April). The neck changes of the 2 groups were coincident over the subsequent winter and spring period (i.e. June-November 1987).

In addition to the observed liveweight and neck girth changes, the melatonin-treated bucks displayed typical rutting behaviour during the early mating period in February, including characteristic vocalizations and aggressive displays.

\section{Discussion}

Previous attempts to manipulate seasonality in fallow deer have produced only marginal results in advancing the occurrence of oestrus and conceptions (Asher \& Macmillan, 1986; Asher \& Smith, 1987) and the onset of male fertility (Asher et al., 1987). However, in the present study, administration of subcutaneous melatonin implants in both sexes has resulted in a marked advancement (up to 8 weeks) of oestrus/conception in all treated does and of rutting activity in the 
treated bucks. The net effect was an advancement of the subsequent fawning season by $6-8$ weeks, effectively shifting the dam's high energy requirements of lactation from early summer into spring, when pasture availability and quality are optimal.

There was little apparent effect of doe age (pubertal $v s$ adult) or previous reproductive status (pregnant $v s$ non-pregnant) on the occurrence of 1 st oestrus for melatonin-treated does or control does. However, due to the high rate of mortality of 1986 fawns born to does receiving initial implants before parturition, only 2 treated does were lactating during the last part of the treatment period. Although both exhibited oestrus and conceived in late February/early March, in line with the other treated does, the effects of lactation on the attainment of fertility in response to melatonin treatment may require further study in light of some previous studies on melatonin administration to lactating red deer hinds (Nowak et al., 1985; Barrell, 1985) in which seasonal advances in oestrous activity were marginal.

The failure of some fallow does to lactate at parturition in 1986, following $\sim 40$ days of melatonin treatment in late pregnancy, suggests that the initiation of lactation in this species may be under a degree of photoperiodic control. This is perhaps influenced by a reduction in prolactin secretion in response to melatonin treatment, as has been demonstrated for adult and pubertal red deer hinds (Nowak et al., 1985; Webster \& Barrell, 1985; Adam et al., 1987). Earlier studies have shown that prolactin is essential for normal initiation of lactation in sheep (Fulkerson et al., 1975; Gow et al., 1983), cows (Karg \& Schams, 1974; Akers et al., 1981) and goats (Hart \& Morant, 1980).

The slightly, but significantly, longer gestation period in 1987 of the melatonin-treated does may also indicate an influence of prevailing photoperiod on the initiation of parturition, although the mechanism by which this may be achieved remains unclear.

Synchrony of oestrus was more pronounced in the control does (10 days) than in the melatonintreated does ( 58 days). The wide spread of oestrus within the treated groups was mainly due to 2 outliers whose dates for oestrus were $4-5$ weeks later than those of their contemporaries. It is therefore apparent that there were differential responses to melatonin treatment, indicating either that the implants were variable in their delivery of melatonin or that single implants elevated blood melatonin concentrations close to the threshold required for a consistent response in fallow deer. Better synchrony of oestrus may be achieved by further raising blood melatonin concentrations by administering double implants.

The cause of the high rates of embryonic loss observed for melatonin-treated (28\%) and the control $(17 \%)$ does is unknown. Because the affected does were barren suggests that the embryonic loss occurred after removal of the buck on 1 June (i.e. $>90$ days gestation for the treated does and $>30$ days gestation for the control does). Such high rates of embryonic loss have not occurred previously within this herd (Asher, 1987). As the losses occurred in the treated and control groups, and were particularly prevalent amongst the younger does, they seem likely to be unrelated to melatonin treatment.

While melatonin treatment did not have significant effects on liveweight changes, there was an apparent reduction in growth rates of pubertal does after implantation, which may indicate a response to treatment. Clearly, reduced growth rates of young does must be taken into consideration in future treatment programmes as low liveweights may affect fertility and maintenance of pregnancy. It is noteworthy that the treated does that failed to maintain pregnancy in the present trial were the lightest does within their respective classes.

All groups of melatonin-treated does had lower mean pre-fawning liveweights than did their herd-mate controls, but there was no significant difference between treated and control does in mean birth weights of their fawns. The rapid increases in doe liveweight that occur in the last 3 months of pregnancy (Asher, 1987) most probably involve more than just growth of the conceptus and may also represent increased accumulation of body fat reserves in preparation for lactation. If so, the accumulation of fat reserves is compromised by shifting the gestation period earlier by 2 months. However, the better pasture quality over the ensuing lactating period may compensate for this, as evidenced by stable liveweights of the treated does over the lactating period. 
The changes in neck girth in the 2 treated bucks were more pronounced than in an earlier study involving oral administration of melatonin (Asher et al., 1987), indicating that the implants may have provided a more effective means of delivering melatonin. Most significantly the treated bucks exhibited normal rutting activity in response to the occurrence of early oestrus in treated does. Such activity (e.g. vocalization) did not occur with control bucks maintained nearby as a bachelor herd, and in earlier studies on the advancement of oestrus and ovulation in fallow does (e.g. using CIDRs + PMSG), untreated sire bucks did not display normal rutting activity in response to induced oestrus (Asher, 1986).

Melatonin implants provide one convenient means for advancing the breeding and fawning seasons of farmed fallow deer. However, the advantages of such manipulations may be outweighed by increased fawn mortality due to inclement weather, as occurred in the present trial. Consideration will need to be given to altering management practices to reduce fawn mortality.

We thank M. Langridge, O. C. Chitty, H. H. Humble and other staff of the Ruakura Agricultural Centre for assistance in animal management and data collection; L. K. Lewis and Mrs P. A. Bullock (Lincoln College) for the melatonin assays; and Miss M. Thurley (Ruakura) for the progesterone assays.

\section{References}

Adam, C.L. \& Atkinson, T. (1984) Effect of feeding melatonin to red deer (Cervus elaphus) on the onset of the breeding season. J. Reprod. Fert. 72, 463-466.

Adam, C.L., Atkinson, T. \& Moir, C.E. (1987) Melatonin lowers plasma prolactin levels in female red deer (Cervus elaphus). J. Pineal Res. 4, 13-20.

Akers, R.M., Bauman, D.E., Capuco, A.V., Goodman, G.T. \& Tucker, H.A. (1981) Prolactin regulation of milk secretion and biochemical differentiation of mammary epithelial cells in periparturient cows. Endocrinology 109, 23-30.

Arendt, J., Symons, A.M., Laud, C.A. \& Pryde, S.J. (1983) Melatonin can induce early onset of the breeding season in ewes. $J$. Endocr. 97, 395-400.

Asher, G.W. (1985) Oestrous cycle and breeding season of farmed fallow deer, Dama dama. J. Reprod. Fert. 75, 521-529.

Asher, G.W. (1986) Studies on the reproduction of farmed fallow deer, Dama dama. Ph.D. thesis, Lincoln College, University of Canterbury, New Zealand.

Asher, G.W. (1987) Conception rates, gestation length, liveweight changes and serum progesterone concentrations during the breeding season and pregnancy of farmed female fallow deer, Dama dama. Proc. 4th AAAP Animal Science Congress, Hamilton, N.Z., p 247.

Asher, G.W. \& Adam, J.L. (1985) Reproduction of farmed red and fallow deer in northern New Zealand. In Biology of Deer Production, pp 217-224. Eds P. F. Fennessy \& K. R. Drew. The Royal Society of New Zealand.

Asher, G.W. \& Macmillan, K.L. (1986) Induction of oestrus and ovulation in anoestrous fallow deer (Dama dama) by using progesterone and GnRH treatment. J. Reprod. Fert. 78, 693-697.

Asher, G.W. \& Smith, J.F. (1987) Induction of oestrus and ovulation in farmed fallow deer (Dama dama) by using progesterone and PMSG treatment. J. Reprod. Fert. 81, 113-118.
Asher, G.W., Barrell, G.K. \& Peterson, A.J. (1986) Hormonal changes around oestrus of farmed fallow deer, Dama dama. J. Reprod. Fert. 78, 487-496.

Asher, G.W., Day, A.M. \& Barrell, G.K. (1987) Annual cycle of liveweight and reproductive changes of farmed male fallow deer (Dama dama) and the effect of daily oral administration of melatonin in summer on the attainment of seasonal fertility. J. Reprod. Fert. 79, 353-362.

Barrell, G.K. (1985) Techniques for artificial manipulation of ovulation in deer. In Proceedings of $a$ Deer Course for Veterinarians; Course No. 2, pp. 126-134. Deer Branch, N.Z. Veterinary Association; Wellington.

Bittman, E.L., Dempsey, R.J. \& Karsch, F.J. (1983) Pineal melatonin secretion drives the reproductive response to daylength in the ewe. Endocrinology 113, 2276-2283.

Bubenik, G.A. (1983) Shift of seasonal cycle in whitetailed deer by oral administration of melatonin. $J$. exp. Zool 225, 155-156.

Chapman, D.I. \& Chapman, N. (1975) Fallow Deer: their History, Distribution and Biology. Terence Dalton Ltd, Lavenham.

English, J., Poulton, A.L., Arendt, J. \& Symons, A.M. (1986) A comparison of the efficiency of melatonin treatments in advancing oestrus in ewes. $J$. Reprod. Fert. 77, 321-327.

Fairclough, R.J., Hunter, J.T. \& Welch, R.A.S. (1975) Peripheral plasma progesterone and utero-ovarian prostaglandin $F$ concentrations in the cow around parturition. Prostaglandins 9, 901-914.

Fraser, S., Cowen, P., Franklin, M., Franey, C. \& Arendt, J. (1983) Direct radioimmunoassay for melatonin in plasma. Clin. Chem. 29, 396-397.

Fulkerson, W.J., McDowell, G.H. \& Fell, L.R. (1975) Artificial induction of lactation in ewes: the role of prolactin. Aust. J. biol. Sci. 28, 525-530.

Gow, C.B., McDowell, G.H. \& Jenkin, G. (1983) The 
importance of prolactin for initiation of lactation in the pregnant ewe. Aust. J. biol. Sci. 36, 357-367.

Hart, I.C. \& Morant, S.V. (1980) Roles of prolactin, growth hormone, insulin and thyroxine in steroidinduced lactation in goats. J. Endocr. 84, 343-351.

Karg, H. \& Schams, D. (1974) Prolactin release in cattle. J. Reprod. Fert. 39, 463-472.

Kennaway, D.J., Gilmore, T.A. \& Seamark, R.F. (1982) Effect of melatonin feeding on serum prolactin and gonadotrophin levels and the onset of seasonal estrous cyclicity in sheep. Endocrinology 110, 1766-1772.

Lincoln, G.A., Fraser, H.M. \& Fletcher, T.J. (1984) Induction of early rutting in male red deer (Cervus elaphus) by melatonin and its dependence on LHRH. J. Reprod. Fert. 72, $339-343$.

Marshall, F.H.A. (1937) On the change over in the oestrous cycle in animals after transference across the equator, with further observations on the incidence of the breeding seasons and the factors controlling periodicity. Proc. R. Soc. B 122, 413-428.
Nett, T.M. \& Niswender, G.D. (1982) Influence of exogenous melatonin on seasonality of reproduction in sheep. Theriogenology 6, 645-653.

Nowak, R., Elmhirst, R.N. \& Rodway, R.G. (1985) A note on the effect of melatonin feeding on the initiation of ovarian activity and on plasma prolactin levels in lactating and non-lactating red deer hinds. Anim. Prod. 40, 515-518.

Poulton, A.L., Symons, A.M., Kelly, M.I. \& Arendt, J. (1987) Intraruminal soluble glass boluses containing melatonin can induce early onset of ovarian activity in ewes. J. Reprod. Fert. 80, 235-239.

Webster, J.R. \& Barrell, G.K. (1985) Advancement of reproductive activity, seasonal reduction in prolactin secretion and seasonal pelage changes in pubertal red deer hinds (Cervus elaphus) subjected to artificially shortened daily photoperiod or daily melatonin treatments. J. Reprod. Fert. 73, $255-260$.

Received 26 April 1988 